Gustavo D'Andrea ${ }^{1}$

Anna Maria Meyer Maciel Rodríguez ${ }^{1}$ Carla Aparecida Arena Ventura ${ }^{1}$ Silvana Martins Mishima ${ }^{1}$

\title{
DIREITO À SAÚDE: UMA PROPOSTA DE CONCEITO PARA A OPERACIONALIZAÇÃO DE PESQUISAS QUALITATIVAS
}

Right to health: A concept proposal for the operationalization of qualitative research

${ }^{1}$ Universidade de São Paulo. Ribeirão Preto/SP, Brasil.

Correspondência: Gustavo D’Andrea. E-mail: dandrea@usp.br.

Recebido em: 19/08/2016. Revisado: 26/10/2016. Aprovado: 04/11/2016. 


\section{RESUMO}

Desde 1988, o direito à saúde tem sido objeto de estudo de investigações tanto no campo da saúde quanto no do direito, sob distintas perspectivas e abordagens. Este trabalho visa a propor um conceito sobre o tema considerando o prisma histórico e sua evolução conceitual para contribuir com a operacionalização das pesquisas qualitativas. Por meio de consulta à literatura técnica e científica sobre o assunto, a partir de sua regulamentação na Constituição Federal de 1988 até o ano de 2015, utilizou-se o descritor "direito à saúde" e o qualificador "história" para elencar os artigos científicos e identificar as perspectivas estudadas. Da leitura dos artigos selecionados, emergiram quatro grandes aspectos: sociopolítico, legislativo, bioético e de demandas específicas na área da saúde, que nortearam a discussão e elaboração do conceito de direito à saúde. Pode-se dizer que a definição de direito à saúde exige contextualização histórica, cultural, política, econômica e social e depende também de sua organização normativa, de sua natureza (individual e coletiva), da responsabilidade moral e do reconhecimento de sua exigibilidade.

\section{Palavras-Chave}

Direito à Saúde; História; Pesquisa Qualitativa.

\section{ABSTRACT}

Since 1988, the right to health has been the focus of research in health and law, under distinct perspectives and approaches. This study aims to propose a concept on the theme, considering the historical viewpoint and its conceptual evolution to contribute to the operationalization of qualitative research. By consulting the technical and scientific literature on the theme, starting with its regulation in the Brazilian Federal Constitution of 1988 until 2015, and using the descriptor "right to health" and the qualifier "history" to list the scientific articles and identify the perspectives studies. Four main aspects emerged from the reading of the selected articles: sociopolitical, legislative, bioethical and specific health demands that guided the discussion and elaboration of the concept right to health. It can be said that the definition of right to health demands a historical, cultural, political, economic and social framework and depends: on its regulatory organization, on its nature (individual and collective), on the moral responsibility and the acknowledgement of its enforceability.

\section{Keywords}

History; Qualitative Research; Right to Health. 


\section{Introdução}

No campo da pesquisa qualitativa, conceitos precisos são essenciais para que o trabalho se desenvolva de forma apropriada ${ }^{1}$. Pensando na carência de um conceito mais pontual sobre direito à saúde, encontra-se em Green ${ }^{2}$ uma perspectiva sobre o uso de um framework conceitual e sua necessária distinção do framework teórico nesse campo de pesquisa. Segundo a autora, teoria e conceito são termos usados de maneira intercambiável quando se trata de frameworks, não havendo na literatura um consenso quanto à diferença entre esses termos. Certo, no entanto, é que os frameworks: "devem estar lá assistindo os pesquisadores para assegurá-los de que seus projetos de pesquisa estão coerentes e para focalizar suas mentes naquilo que suas pesquisas estão tentando alcançar”3. (Tradução livre.)

Green $^{4}$ ainda frisa que é necessário fazer um esforço para tornar mais clara a linguagem científica, em especial, para auxiliar futuros pesquisadores na construção de seus projetos e, nesse sentido, os frameworks desempenham um papel relevante para a realização dessa tarefa.

Considerando que a elaboração de trabalhos conceituais interdisciplinares na área de direito à saúde é atividade ainda rara no Brasil e que o presente estudo não tem o objetivo de investigar uma teoria específica, é suficiente embasá-lo na noção trazida por Rocco e Plakhotnik ${ }^{5}$, enfatizando-se que um framework conceitual alicerça o estudo em bases de conhecimento relevantes que estabelecem os fundamentos para a importância da declaração do problema e das perguntas de pesquisa.

Acrescenta-se que este estudo constitui o que Rocco e Plakhotnik ${ }^{6}$ classificam como sendo um tipo de manuscrito, pois, assim como um framework conceitual, relaciona conceitos, pesquisa empírica e teorias relevantes para apresentar e sistematizar o conhecimento sobre conceitos ou questões relacionados.

Dito isso, este artigo busca explorar a literatura científica sobre o tema do direito à saúde e tecer comentários no sentido de propor uma alternativa de conceito funcional para essa área de estudo. Por conceito funcional, entende-se um sólido

\footnotetext{
${ }^{1}$ MINAYO, Maria Cecília de Souza. O desafio do conhecimento: pesquisa qualitativa em saúde. 14. ed. São Paulo: Hucitec, 2014.

${ }^{2}$ GREEN, Helen Elise. Use of theoretical and conceptual frameworks in qualitative research. Nurse Researcher, London, v. 21, n. 6, p. 34-38, Jul. 2014. Disponível em: <http://journals.rcni.com/doi/pdfplus/10.7748/ nr.21.6.34.e1252>. http://dx.doi.org/10.7748/nr.21.6.34.e1252.

${ }^{3}$ Id. Ibid., p. 35. No original: "It can be seen that the authors are saying that the framework should be there to assist researchers in ensuring that their research projects are coherent and to focus their minds on what the research is trying to achieve."

${ }^{4}$ Id. Ibid.

${ }^{5}$ ROCCO, Tonette S.; PLAKHOTNIK, Maria S. Literature reviews, conceptual frameworks, and theoretical frameworks: terms, functions, and distinctions. Human Resource Development Review, Thousand Oaks, v. 8, n. 1, p. 120-130, Mar. 2009. Disponível em: <https://www.researchgate.net/publication/249673870>. http://dx.doi.org/10.1177/1534484309332617.

${ }^{6}$ Id. Ibid.
} 
posicionamento que pode orientar estudos, intervenções e capacitações. Assim, a construção de um conceito não abrange apenas seus aspectos objetivos, pois:

\begin{abstract}
Todo conceito é historicamente construído e para se entender seu alcance ou para reformulá-los, nas ciências sociais, se preconiza que sejam analisados em sua origem e percurso, de forma crítica. [...] Portanto, na formulação de uma pesquisa, não é o suficiente compreendê-los como operações lógicas e se estão corretamente concatenados. É preciso, além disso, entender o sentido histórico e sociológico de sua definição e das combinações que produzem ${ }^{7}$.
\end{abstract}

Tendo essa afirmação como premissa para compreender os significados de conceitos que se apresentam como fundamentais na vida em sociedade em determinado contexto político, social e histórico, busca-se entender a inter-relação entre direito e saúde considerando sua diversidade conceitual e, ao mesmo tempo, direcionar essa interpretação para a formulação de uma proposta de conceito embasadora para pesquisas qualitativas.

Apesar dessa pluralidade de significados, é escassa a literatura científica que se propõe a oferecer uma definição que dê conta da compreensão que hoje se procura dar a essa inter-relação, embora em cada área (direito e saúde) os materiais conceituais sejam abundantes.

O vocabulário jurídico define direito como um complexo orgânico do qual derivam as normas e os deveres que regem as relações entre os homens em determinada sociedade. Compreender e explicar o significado da palavra direito é uma tarefa extremamente complexa e tem ocupado discussões de diversas naturezas. $\operatorname{Hart}^{8}$ já tratava da abundância de material escrito sobre a questão do conceito de direito. Não se pretende entrar a fundo nas discussões jusfilosóficas a respeito do que se deve entender por essa palavra, pois esse tipo de discussão ultrapassaria os objetivos do presente artigo.

Além disso, como se objetiva entender como determinados autores conceituaram o direito à saúde, talvez seja mais prudente não tentar definir uma ou outra forma pela qual o direito possa ser entendido, bastando que se tenha a noção de o direito ter, na língua portuguesa, pelo menos três acepções: a relacionada ao próprio direito como campo de estudo (por exemplo, quando se faz referência às faculdades de direito); a que remete ao ordenamento jurídico de determinado território (a exemplo do Direito Brasileiro); e o direito como um atributo do ser humano, geralmente ligado à noção de "posse", ou seja, ter ou não ter determinado direito, o que implica em ter ou não ter a faculdade de exercê-lo.

${ }^{7}$ MINAYO, Maria Cecília de Souza. op. cit., p. 177

${ }^{8}$ HART, Herbert Lionel Adolphus. O conceito de direito. 2. ed. Lisboa: Fundação Calouste Gulbenkian, 1994. 
Na mesma direção de não aprofundar conceitualmente o direito, não se pretende definir previamente um conceito de Saúde, mas é importante ter a noção de que esta também possui várias acepções. Por exemplo, de um ponto de vista mais geral, a Organização Mundial da Saúde (OMS), em 1946, definiu saúde como completo bem-estar físico, mental e social ${ }^{9}$. De outra forma, à luz de seu significado etimológico, saúde pode ser descrita, também, como a conservação da vida que permite o exercício normal de todas as funções fisiológicas do corpo ${ }^{10}$. De um ponto de vista legal, a partir de 1988 no Brasil, a saúde passou a ser definida como direito de todos e dever do Estado, integrando um dos direitos sociais previstos constitucionalmente ${ }^{11}$.

Ciente de que normas, direitos e deveres, sociedade e saúde são objetos de investigação ao longo da história da conformação da humanidade, este estudo se propõe a abordar o direito à saúde, buscando explorar sua definição com base em um panorama referente a artigos de periódicos nacionais e internacionais nos quais os autores se preocuparam em, de alguma forma, conceituar o tema, do ponto de vista histórico.

\section{Método}

Entender como os autores tratam da evolução do conceito de direito à saúde até os dias atuais definiu o método exploratório de busca pela literatura. Na primeira etapa da elaboração deste estudo, foi realizada uma consulta à literatura científica e técnica sobre o tema "direito à saúde" na Biblioteca Virtual em Saúde (Bireme) - que abrange uma coleção de fontes de informação, tais como Lilacs, Ibecs, Medline e Scielo - buscando artigos científicos que abordassem diferentes definições de direito à saúde do ponto de vista histórico.

Estabeleceu-se como descritor - com base na relação de Descritores em Ciências da Saúde (DeCS) da Bireme - a expressão "direito à saúde", adicionando o qualificador "história", haja vista a importância desse aspecto para a compreensão de conceitos nas pesquisas qualitativas. Segundo o DeCS ${ }^{12}$ (edição 2016), "direito à saúde" é definido como "um dos direitos humanos fundamentais assegurado na Constituição, que permite aos cidadãos exigirem do Estado as condições para que possam gozar de completo bem-estar físico, mental e social"; e o qualificador "história" é direcionado para "aspectos históricos de um assunto", incluindo "notas históricas breves" e excluindo "histórias de casos".

\footnotetext{
9WORLD HEALTH ORGANIZATION. Constitution. 1946. Disponível em: <http://www.who.int/governance/eb/ who_constitution_en.pdf>. Acesso em: 14 maio 2016.

${ }^{10}$ SILVA, Plácido. Vocabulário jurídico. 27. ed. Rio de Janeiro: Forense, 2008.

${ }^{11}$ BRASIL. Constituição da República Federativa do Brasil de 1988. Disponível em: <http://www.planalto.gov. br/ccivil_03/constituicao/constituicaocompilado.htm>. Acesso em: 12 jul. 2016.

${ }^{12}$ BIBLIOTECA VIRTUAL DA SAÚDE. Descritores em Ciências da Saúde 2016. Disponível em: <http://decs.bvs. br/cgi-bin/wxis1660.exe/decsserver/>. Acesso em: 31 Maio 2017.
} 
O período de busca foi delimitado entre os anos de 1988 (data da promulgação da Constituição Federal hoje em vigor, de $1988-\mathrm{CF} / 88^{13}$ ) e 2015. Inicialmente, foram encontradas 41 produções, das quais 14 eram artigos publicados em periódicos (11 escritos na língua portuguesa, dois na espanhola e um na inglesa). As demais 27 foram excluídas, pois se referiam a painel, editorial, teses, livros e capítulos de livros, DVD e fita de videocassete ou se repetiram no processo de busca. Os 14 artigos selecionados foram lidos exaustivamente na íntegra em um primeiro momento, para em seguida serem discutidos e sintetizados com base no objetivo central da investigação, o que resultou em quatro grandes aspectos relevantes sobre o tema: legislativo, sociopolítico, bioético e aspecto específico da saúde mental.

Mediante os achados, o trabalho conclui propondo um conceito funcional sobre $\mathrm{o}$ assunto, a ser útil para a operacionalização de análises em pesquisas qualitativas.

\section{Resultados}

\section{0 direito à saúde no aspecto legislativo}

Dallari et al..$^{14}$ definem saúde como um direito social - à luz da $\mathrm{CF} / 88^{15}$ - e dever do Estado, pontuando normas legislativas e estratégias da advocacia em saúde como norteadoras de sua prestação, na esfera individual ou coletiva.

Nesse mesmo sentido, Yamin ${ }^{16}$ afirma que a proteção da saúde está garantida na Constituição Mexicana por meio da ação governamental e das metas estabelecidas pelo Sistema Nacional de Salud que, entre outras medidas, deve prover serviços básicos de qualidade no setor a toda a população. Entretanto, a legislação não estabelece os mecanismos para se efetivar o direito à saúde, e sim apenas respalda as denúncias - perante os tribunais - referentes a má prática ou negligência médica que possa ter provocado danos à saúde. A autora acrescenta ainda que o direito à saúde envolve o bem-estar, a educação, a alimentação, o trabalho e outros direitos econômicos e sociais reconhecidos também em vários tratados internacionais ${ }^{17}$. Além disso, descreve a relevância de técnicas médicas (patologia e antropologia forenses) no processo de documentação da violação dos direitos civis no México, retratando os efeitos dos casos de torturas e execuções sobre a saúde, bem como outras habilidades médicas úteis (epidemiologia e estatística) na promoção dos

\footnotetext{
${ }^{13}$ BIBLIOTECA VIRTUAL DA SAÚDE. op. cit.

${ }^{14}$ DALLARI, Sueli Gandolfi et. al. Advocacia em saúde no Brasil contemporâneo. Revista de Saúde Pública, São Paulo, v. 30, n. 6, p. 592-601, 1996. Disponível em: <http://www.scielo.br/pdf/rsp/v30n6/5117.pdf>. http://dx.doi.org/10.1590/S0034-89101996000600014.

${ }^{15}$ Id. Ibid.

${ }^{16}$ YAMIN, Alicia Ely. Dignidad y bienestar. El valor de las técnicas y metodologías médicas en la promoción de los derechos humanos: el caso estudio de México. Cuadernos Médico Sociales, Rosário, n. 74, p. 5-23, 1998. Disponível em: <http://hdl.handle.net/1928/4613>. Acesso em: 20 nov. 2015.

${ }^{17}$ Id. Ibid.
} 
direitos econômicos e sociais. Nesse caso, o acesso a condições de vida saudáveis e a serviços/cuidados de saúde primários e essenciais pode mensurar a implementação desses direitos ${ }^{18}$.

Além da abordagem do direito à saúde de forma geral, Padrão ${ }^{19}$ enfoca o direito à saúde mental, expondo o avanço da legislação psiquiátrica no Brasil. Também pontua as bases legais que incorporam o direito à saúde mental como ampliação do direito social à saúde, propondo a humanização dos tratamentos de saúde mental, a regulamentação da internação involuntária, o resgate da dívida social com os institucionalizados, a reorientação da aplicação dos recursos públicos destinados aos cuidados na área e a operacionalização do processo democrático da reforma psiquiátrica brasileira.

Observa-se que, de maneira geral, no aspecto legislativo do direito à saúde, os autores destacaram a positivação de normas relacionadas à proteção desse direito social, em âmbito nacional ou internacional, por meio de constituições federais e tratados internacionais.

\section{O direito à saúde no aspecto sociopolítico}

Nos dizeres de Gracia:

Ao longo do último século, a saúde deixou de ser um problema privado concernente principalmente a indivíduos e se tornou um problema público, uma questão política. Os termos "saúde" e "política", de início mutuamente excludentes, tornaram-se inextrincavelmente entrelaçados na expressão "política de saúde”, até hoje sendo difícil encontrar qualquer aspecto da saúde completamente desconectado do imenso aparato da política de saúde ${ }^{20}$. (Tradução livre.)

Enfatizam-se dois momentos da justiça na saúde: o deontológico (orientado por princípios) e teleológico (orientado pelas consequências ou resultados). Haveria uma dialética obrigatória entre esses dois momentos, de modo que, "nas questões relacionadas à justiça distributiva em saúde, a ética parece ignorar a política e a

\footnotetext{
${ }^{18}$ YAMIN, Alicia Ely. op. cit.

${ }^{19}$ PADRÃO, Messias Ligouri. O estatuto do doente mental. Saúde em Debate, Rio de Janeiro, n. 37, p. 11-15, dez. 1992.

${ }^{20}$ No original: "Over the last century health has ceased to be a private matter concerning mainly individuals and has become a public problem, a political issue. The terms "health" and "politics," initially mutually exclusive, have become inextricably intertwined in the expression "health policy," until today it is hard to find any aspect of health completely detached from the immense bureaucratic apparatus of health policy." GRACIA, Diego. What constitutes a just health services system and how should scarce resources be allocated? Bulletin of the Pan American Health Organization, Washington, v. 24, n. 4, p. 550-565, 1990. Disponível em: <http://hist.library.paho.org/English/BUL/ev24n4p550. pdf>. Acesso em: 20 dez. 2015. p. 550.
} 
economia, as quais por sua vez decidiram ignorar a ética, senão suplantá-la; e isto parece constituir uma forma grave de injustiça"21 (tradução livre).

Paiva $^{22}$ afirma que o conceito de direito à saúde deve ser analisado sob dois pontos de vista: o individual e o coletivo. A autora se reporta às explicações de Dallari ${ }^{23,24}$, frisando que o aspecto individual está ligado à liberdade do paciente e do profissional; enquanto o coletivo, à saúde como elemento público e o direito à saúde em sua ligação com a igualdade, inclusive se contrapondo à liberdade, quando necessária sua limitação em favor do bem coletivo. Embora não seja consenso a possibilidade de equilíbrio entre os dois aspectos, há concordância geral de que a saúde é contextualizada social e politicamente, o que influencia as políticas públicas no setor. Reportando-se novamente a Dallari ${ }^{25}$, a autora enfatiza a necessidade de que a saúde e o direito à saúde sejam definidos no nível local, com a participação da comunidade na decisão sobre o equilíbrio entre liberdade e igualdade.

Sposati e $L_{o b o}{ }^{26}$ reafirmam a saúde como produto social e histórico - semelhantemente a Dallari ${ }^{27,28}$ e Gornes e Adorno ${ }^{29}$, apontando nas três esferas de Poder mecanismos representativos de inserção, reivindicação e fiscalização popular na área que podem democratizar o complexo conceito de direito à saúde.

Novaes $^{30}$, trazendo como exemplo a prática homeopática, discute a aceitação da homeopatia como prática de saúde e especialidade médica, indicando suas raízes históricas, seus princípios doutrinários, suas limitações e contradições, bem como as transformações políticas, econômicas, sociais, científicas, administrativas e institucionais na esfera da saúde que permitiram seu reconhecimento como proposta terapêutica, pelo menos entre a parcela da população que busca e acredita nesse tratamento.

\footnotetext{
${ }^{21}$ No original: "In other words, in issues related to distributive justice in health, ethics appears to have ignored economics and politics, which in turn have decided to ignore ethics, if not supplant it; and this appears to constitute a serious form of injustice." GRACIA, Diego. op. cit., p. 565.

${ }^{22}$ PAIVA, Miriam Santos. O direito à saúde. Revista Baiana de Enfermagem, Salvador, v. 4, n. 2, p. 63-79, dez. 1988.

${ }^{23}$ DALLARI, Sueli Gandolfi. A saúde do brasileiro. São Paulo: Moderna, 1978.

${ }^{24}$ DALLARI, Sueli Gandolfi. O direito à saúde. Revista de Saúde Pública, São Paulo, v. 22, n. 1, p. 57-63, 1988. Disponível em: <http://www.scielo.br/pdf/rsp/v22n1/08.pdf>. Acesso em: 14 jan. 2016.

${ }^{25}$ DALLARI, Sueli Gandolfi. $A$ saúde do brasileiro, cit.

${ }^{26}$ SPOSATI, Aldaísa; LOBO, Elza. Controle social e políticas de saúde. Cadernos de Saúde Pública, Rio de Janeiro, v. 8, n. 4, p. 366-378, out./dez. 1992. Disponível em: <http://www.scielo.br/pdf/csp/v8n4/ v8n4a03>. http://dx.doi.org/10.1590/S0102-311X1992000400003.

${ }^{27}$ DALLARI, Sueli Gandolfi. A saúde do brasileiro, cit.

${ }^{28}$ DALLARI, Sueli Gandolfi. 0 direito à saúde, cit.

${ }^{29}$ GORNES, Fabíola Zioni; ADORNO, Rubens de Camargo Ferreira. Criança e menor na sociedade brasileira: serviços, cuidados e exclusão. Revista Brasileira de Crescimento e Desenvolvimento Humano, São Paulo, v. 1, n. 1, p. 41-48, jan./jun. 1991. Disponível em: <http://www.revistas.usp.br/jhgd/article/ viewFile/37412/40127>. Acesso em: 10 fev. 2016. http://dx.doi.org/10.7322/jhgd.37412.

${ }^{30}$ NOVAES, Ricardo Lafetá. Sobre a homeopatia. Saúde em Debate, Rio de Janeiro, n. 23, p. 85-94, dez. 1988.
} 
Apesar de o autor trazer para discussão esse aspecto específico relacionado indiretamente ao direito à saúde, ele tece comentários mais genéricos sobre a relevância da organização popular para a reivindicação e a conquista de melhores condições de trabalho, moradia, alimentação, educação, vestuário e saúde, relacionadas à consciência da condição de cidadania ${ }^{31}$.

No que diz respeito à homeopatia, o autor afirma que a oferta de seu uso advém, muito mais, dos esforços de homeopatas do que de exigências dos usuários. E sustenta, também, a posição de que a homeopatia, assim como os demais procedimentos médicos, deve se submeter à permanente avaliação para legitimar seus riscos potenciais e sua (in)eficácia como terapêutica complementar ${ }^{32}$.

Para abordar a evolução da atenção à saúde da criança no Brasil e alguns aspectos do desenvolvimento e crescimento infantil, Gornes e Adorno ${ }^{33}$ afirmam, primeiramente, que a saúde é produto das relações políticas, sociais e econômicas produzidas historicamente em uma sociedade, sendo essa conjuntura responsável também pela organização dos serviços no setor. Dialogando com essa premissa, pontuam os períodos históricos (desde o período colonial até meados da década de 1980) e seus principais acontecimentos, descrevendo a forma pela qual os cuidados de saúde eram oferecidos às crianças e traçando um perfil de implantação das práticas na área para esse público.

$P a d r a ̃ o^{34}$, além de assinalar o quadro jurídico que respalda o movimento da Reforma Psiquiátrica Brasileira, contextualiza, de maneira concisa, o cenário internacional de assistência às pessoas com transtornos mentais. $\mathrm{O}$ autor afirma que, em vários países, as reformas constitucional e assistencial nessa área têm se mostrado efetivas mediante o envolvimento ativo da sociedade civil, pessoas com transtornos mentais e seus familiares.

Assis, Gonçalves e Matos $^{35}$, na década de 1990, entendem o direito à saúde como sendo uma noção básica para a formulação de políticas públicas, considerando a história de lutas pelo acesso abrangente da população à saúde - ou democratização da saúde - tal como apontado pelos autores anteriormente citados. O tema foi tratado no âmbito de uma crítica à lógica da Atenção Primária em Saúde brasileira, em especial no que se referia à falta de articulação entre redes de atendimento com desdobramentos negativos em termos administrativos e financeiros. As autoras fizeram referência a alternativas reformistas que visassem a transformar a situação

\footnotetext{
${ }^{31}$ NOVAES, Ricardo Lafetá. op. cit.

${ }^{32}$ Id. Ibid.

${ }^{33}$ GORNES, Fabíola Zioni; ADORNO, Rubens de Camargo Ferreira. op. cit.

${ }^{34}$ PADRÃO, Messias Ligouri. op. cit.

${ }^{35}$ ASSIS, Marluce Maria Araújo; GONÇALVES, Maria de Lourdes; MATOS, Maria Socorro. Atenção primária de saúde x sistema único de saúde: apontamentos para um debate. Revista Baiana de Enfermagem, Salvador, v. 6, n. 2, p. 78-88, out. 1993.
} 
precária do setor por meio de mudanças jurídicas, anotando, no entanto, a ineficácia de avanços jurídicos observados. A municipalização, nesse sentido, era vista como ponto central das políticas reformistas. Criticam, nesse contexto, o projeto "neoliberal" e reafirmam a necessidade de mudanças para combater a hegemonia desse modelo, fortalecendo a descentralização e frisando a importância de que o cidadão seja ativo, social e politicamente, a fim de garantir seus direitos.

Nessa direção, Santos $^{36}$ descreve a mobilização de trabalhadores rurais no interior do Maranhão em prol de direitos sociais. $\mathrm{O}$ autor narra a luta camponesa pelo direito ao cultivo/extrativismo e livre acesso aos babaçuais, em um cenário político dominado por latifundiários grileiros. Esse movimento agrário, que inicialmente buscou a sobrevivência coletiva imediata, transformou-se em aspiração pela melhoria das condições sanitárias e atenção às demandas de saúde dessa comunidade.

Feuerwerker ${ }^{37}$ aborda o tema destacando o contexto político e social no qual tem sido constituído o sistema público de saúde no Brasil - representado pelo Sistema Único de Saúde (SUS). Inicialmente, a autora enfatiza o papel da reforma sanitária como movimento precursor do direito à saúde universal e equânime. Em seguida, realça a organização: do modelo tecnoassistencial, das políticas de saúde, da participação social, de gestão, práticas e serviços do setor, além do enfrentamento dos determinantes do processo saúde-doença como elementos centrais para se produzir, sustentar e recriar a concepção de saúde e se concretizar esse direito social ${ }^{38}$.

Nota-se que as produções, agrupadas no aspecto político e social do direito à saúde, demonstram a relevância dessas condições, em especial a interação popular, para se delinear o processo histórico de oferta, garantia, produção e definição das políticas públicas e, consequentemente, do direito à saúde.

\section{3. $\quad 0$ direito à saúde no aspecto bioético}

Guchea $^{39}$ expõe os modelos éticos de referência prática no campo da medicina, evidenciando alguns dilemas morais da sociedade. Nesse aspecto, o autor problematiza a questão da saúde de diversas maneiras. Na primeira, questiona se a saúde é um direito ou um bem de mercado, afirmando que pode induzir a um rol

\footnotetext{
${ }^{36}$ SANTOS, Luis A. de Castro. A vez da mulher camponesa: movimento social, identidade e saúde no Maranhão. Revista Brasileira de Estudos de População, Rio de Janeiro, v. 20, n. 1, p. 43-62, jan./jun. 2003. Disponível em: <http://rebep.org.br/index.php/revista/article/viewFile/303/pdf_284>. Acesso em: 13 fev. 2016.

${ }^{37}$ FEUERWERKER, Laura. Modelos tecnoassistenciais, gestão e organização do trabalho em saúde: nada é indiferente no processo de luta para a consolidação do SUS. Interface, Botucatu, v. 9, n. 18, p. 489-506, set./dez. 2005. Disponível em: <http://www.scielosp.org/pdf/icse/v9n18/a03v9n18.pdf>. Acesso em: 18 fev. 2016. http://dx.doi.org/10.1590/S1414-32832005000300003.

${ }^{38}$ Id. Ibid.

${ }^{39}$ GÓMEZ GUCHEA, Hugo Francisco. Ética médica. Revista Medica de Tucumán, Tucumán, v. 8, n. 3, p. 109-116, 2002.
} 
de cuidados e serviços que se organiza mediante a distribuição de riquezas, se for caracterizada como um item de consumo,

Na segunda, questiona se esse conjunto básico de prestações pode ser uma obrigação ética com sentido de beneficência e, na terceira, se as reformas na área realmente melhoram as condições sanitárias da população ou apenas controlam os gastos em saúde. Na quarta, a pergunta é se a teoria da equidade pode ser um valor ético para que se resolva o impasse entre o que é necessário e o que é possível garantir no setor. Na quinta, sexta, sétima e oitava formas, o autor contesta a relação entre recursos disponíveis, gastos na área, corrupção e sujeitos do direito à saúde. E, na última, sugere limitar esse direito social considerando a relação custo-benefício e a alocação ética dos recursos ${ }^{40}$.

Embora nesse aspecto haja apenas uma referência, trata-se de um tema relevante e digno de nota, pois a perspectiva bioética acaba complementando os aspectos anteriores (legislativo e sociopolítico), trazendo questões relativas à discussão sobre "a coisa certa a fazer", tais como a equidade, os dilemas morais e o valor da saúde.

\section{0 direito à saúde no aspecto específico da saúde mental}

Quinto Neto ${ }^{41}$ escreveu nos anos 1990 um artigo voltado à saúde mental que pode nos trazer alguns insights a respeito do direito à saúde nesse âmbito, de modo que vale uma análise mais detida de seu conteúdo. Remonta o autor à década de 1960, quando advogados atuaram na defesa de direitos civis no âmbito internacional, concentrando-se na temática da saúde mental e, inicialmente, pensando no direito ao tratamento e sua recusa.

Depois de expor uma breve linha histórica sobre o surgimento da interferência legislativa no campo da saúde mental, Quinto Neto ${ }^{42}$ argumenta que a legislação representa um agente transformador poderoso no campo da saúde, atuando como um elemento que limitaria os riscos à saúde. Especifica, então, o papel da legislação no campo da saúde mental, fazendo referência indireta ao documento Dimensiones Sociales de la Salud Mental, da Organização Pan-Americana da Saúde de 1983. O autor constrói, então, um pensamento que permite inferir uma possível acepção para o termo "direito à saúde":

No caso específico da Saúde Mental, as leis podem influir favoravelmente na criação de possibilidades de humanização dos procedimentos aplicados, facilitar o surgimento e a instalação de meios que permita $[s i c]$ à sociedade enfrentar, de forma social e humanamente aceitável, os desvios de comportamento, e proteger os direitos e a integridade das pessoas em sofrimento psíquico ${ }^{43}$.

\footnotetext{
${ }^{40}$ GÓMEZ GUCHEA, Hugo Francisco. op. cit.

${ }^{41}$ QUINTO NETO, Antônio. A reforma psiquiátrica no Rio Grande do Sul: do direito ao tratamento aos direitos de cidadania do doente mental. Saúde em Debate, Rio de Janeiro, n. 37, p. 5-10, dez. 1992.

${ }^{42}$ Id. Ibid.

${ }^{43}$ Id. Ibid., p. 6.
} 
Ao discorrer especificamente sobre a lei gaúcha a respeito da reforma psiquiátrica, Quinto Neto ${ }^{44}$ destaca cinco pontos estruturais em seu conteúdo, sendo eles: a municipalização para facilitar o atendimento na comunidade; a participação social; a preservação dos direitos de cidadania do doente mental; a reestruturação da atenção psiquiátrica; e a integração da saúde mental ao sistema de saúde geral e aos serviços sociais. Além disso, destaca aspectos operacionais da Lei de Reforma Psiquiátrica:

A aplicação do princípio da autonomia na relação cuidador-cuidado, que vem progressivamente substituindo o princípio da beneficência, trouxe ao cenário da atenção à saúde uma nova ética: agora o usuário pode decidir sobre o que é melhor para si. Este fato está alterando radicalmente a estrutura da tradicional relação médico-paciente que se encontra em franca crise existencial ${ }^{45}$.

O autor faz menção, também, ao aspecto coletivo da satisfação das necessidades de saúde mental, ao lado do aspecto individual. É algo a se considerar.

Pitta e Dallari ${ }^{46}$, também nos anos 1990, abordam a equidade como sendo uma nova utopia, definindo-a como "a disposição de atender igualmente aos direitos de cada um"47. Assim, há a substituição da "homogeneidade, a pasteurização dos sujeitos pelo reconhecimento das suas singularidades"48.

As autoras destacam alguns dos direitos específicos das pessoas com transtornos mentais, previstos em documentos legislativos de outros países ou internacionais: direito ao tratamento e também o de não se submeter a tratamento; direito de preservar sua capacidade civil; direito de ser ouvido; e direito ao segredo médico. Destacam, ainda, o papel do município, enquanto ente apto e autônomo, na busca de uma concretização mais realista e localizada dos direitos desse público, frisando esse caminho como sendo o que permitiria a conquista diária da cidadania:

Se os critérios epidemiológicos devem ser os que presidem e respaldam decisões político-técnicas para o setor, de pronto deve-se observar que não será apenas com uma rede especializada em cuidados mentais que será possível enfrentar tal dimensão epidemiológica. A integralidade das ações, assistindo adequadamente corpo e vida psicossocial, deverá estar sendo perseguida na totalidade dos espaços assistenciais, respeitando critérios de acessibilidade, complexidade pertinente, efetividade, eficácia,

\footnotetext{
${ }^{44}$ QUINTO NETO, Antônio. op. cit.

${ }^{45}$ Id. Ibid., p. 9.

${ }^{46}$ PITTA, Ana Maria Fernandes; DALLARI, Sueli Gandolfi. A cidadania dos doentes mentais no sistema de saúde do Brasil. Saúde em Debate, Rio de Janeiro, n. 36, p. 19-23, out. 1992.

${ }^{47}$ Id. Ibid., p. 21.

${ }^{48}$ Id. loc. cit.
} 
obedecendo a uma plasticidade de serviços para fazer face à diversidade da demanda ${ }^{49}$.

Nota-se, nesse aspecto, que os autores citados tentaram explicar e contextualizar o direito à saúde utilizando-se de áreas específicas - no caso, a saúde mental - tal como o fez Padrão ${ }^{50}$, citado anteriormente na apresentação do aspecto legislativo do direito à saúde, para esclarecer o processo de desenvolvimento da assistência nesse campo. O tema merece integrar o conjunto dos aspectos conceituais do direito à saúde, não por ser referente especificamente à área de saúde mental, mas por ser um claro exemplo de como os outros três aspectos (legislativo, sociopolítico e bioético) acabam convergindo quando se observa um campo específico de atenção à saúde que também envolve participação social, cidadania e equidade nas ações e serviços de saúde.

A partir desses achados na literatura científica, pode-se propor um conceito de direito à saúde útil para as pesquisas qualitativas.

\section{O processo de reflexão e proposição de um conceito de direito à saúde}

O rastreamento de artigos científicos realizado para os objetivos deste trabalho foi limitado pela escassez de estudos que, de forma específica, se direcionassem para a contextualização histórica do direito à saúde. O uso de descritor combinado com um qualificador - no caso, "direito à saúde/história" - resultou em número limitado de artigos. Isso não significa que sejam esses os únicos que abordam o direito à saúde sob um prisma histórico, mas, atendendo ao proposto, permitiu aproximação à possibilidade de refletir sobre o conceito.

Neste processo e com base nos achados, pode-se afirmar que não há um conceito definitivo de direito à saúde. Três são os motivos para essa consideração:

(a) a revisão possui a limitação mencionada, de modo que somente um trabalho de revisão exaustivo poderia esgotar toda a amplitude de significados possíveis para o direito à saúde;

(b) "direito à saúde" apresentou-se como expressão com significados contextualizados, variando conforme os objetos de estudo e os respectivos momentos históricos, de modo que, mesmo com uma eventual revisão exaustiva, o decurso do tempo poderia fazer surgirem outros conceitos e acepções; e

(c) Embora sendo um direito antigo, sua regulamentação mais concreta é recente, especialmente enquanto direito social previsto na $\mathrm{CF} / 88^{51}$, o que leva à expectativa de novos avanços em seu significado e em seus desdobramentos práticos.

\footnotetext{
${ }^{49}$ PITTA, Ana Maria Fernandes; DALLARI, Sueli Gandolfi. op. cit., p. 19.

${ }^{50}$ PADRÃO, Messias Ligouri. op. cit.

${ }^{51}$ BRASIL. Constituição da República Federativa do Brasil de 1988, cit.
} 
Os achados permitem representar os diversos aspectos conceituais do direito à saúde na forma da Figura 1.

Entretanto, a Figura 1 possui elementos específicos relacionados aos limites de cada artigo consultado, não encerrando a totalidade dos desdobramentos possíveis de cada aspecto. Com o intuito de generalizar essas dimensões, as especificidades e as linhas interpretativas que conduziram a compreensão dos autores de acordo com seus respectivos escopos foram omitidas. Assim, na Figura 2 está representada uma estrutura para a construção de um conceito de direito à saúde para as pesquisas qualitativas.

Os quatro aspectos do conceito de direito à saúde encontrados na literatura estão representados dentro de um círculo denominado contexto, a fim de frisar que a noção conceitual deve estar sempre referenciada contextualmente - sendo fundamental que o pesquisador busque compreender o âmbito no qual se insere sua própria pesquisa, com base em um máximo de critérios possíveis, tais como a população-alvo, o território em que a coleta de dados é realizada, o momento histórico contemporâneo e sua relação com antecedentes e tendências.

Dos aspectos conceituais, os três primeiros (legislativo, sociopolítico e bioético) seguem a categorização realizada na análise dos resultados. O quarto aspecto sofre uma pequena alteração para que possa ser generalizado e, conforme o caso, novamente especificado. Os resultados mostram que o último aspecto refere-se

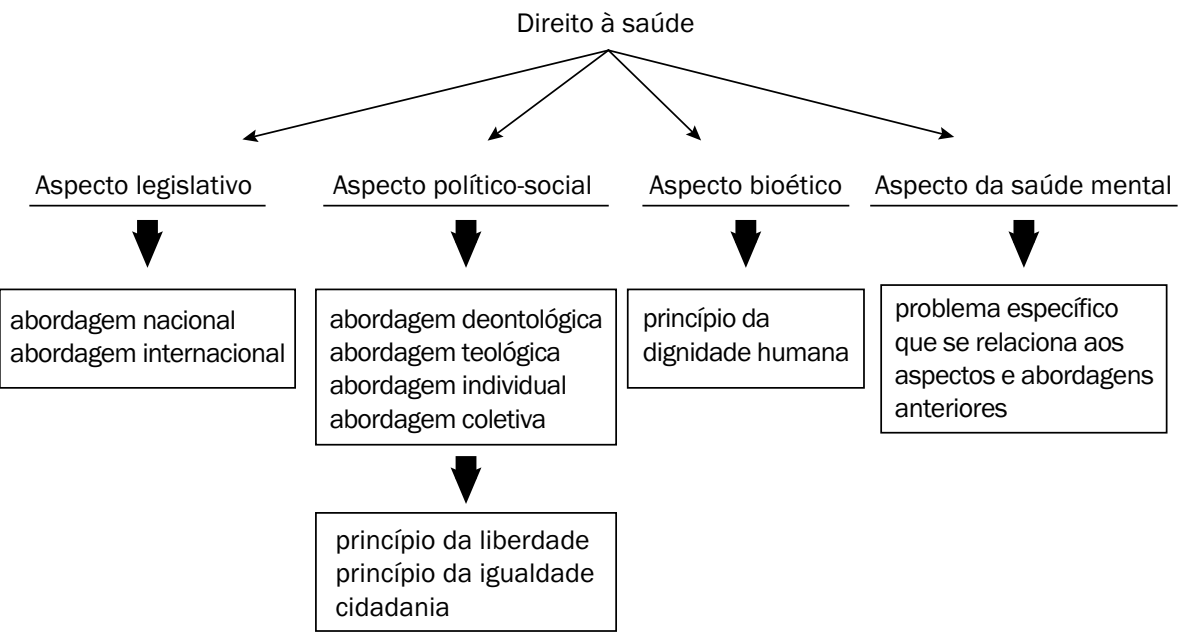

Contexto social, econômico, político, histórico, cultural

Figura 1. Representação dos aspectos conceituais do direito à saúde segundo consulta bibliográfica. 


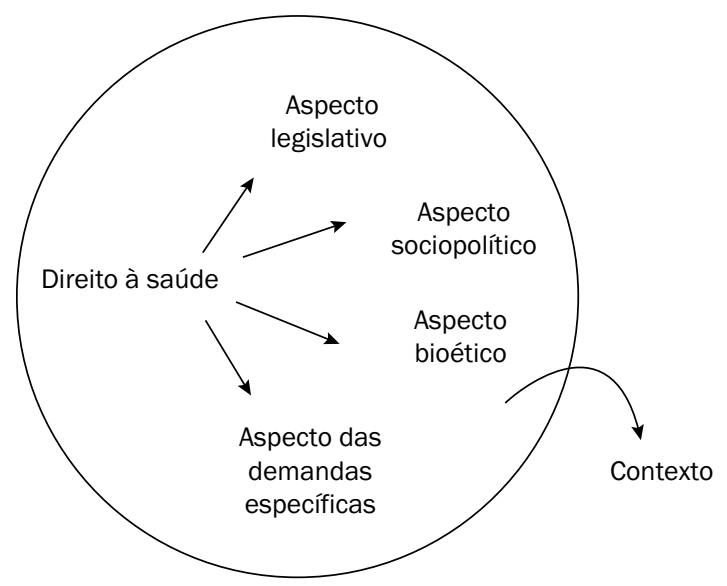

Figura 2. Representação dos elementos para construção de um conceito de direito à saúde para pesquisas qualitativas.

especificamente à saúde mental, mas que a interpretação correta desse achado é assumir que a construção histórica do conceito de direito à saúde encontrará realidades diferentes, conforme a área da saúde ou o problema específico de saúde que esteja sendo estudado. Por isso, o quarto aspecto, para ser generalizado, deve se referir abstratamente a demandas específicas de saúde.

O conceito a que se pode, assim, chegar para o direito à saúde, pensando em uma função mais voltada para a operacionalização de pesquisas qualitativas, envolve sempre considerar tal conceito como sendo primeiramente contextualizado. Com essa consideração em mente e com base nos resultados da consulta realizada na literatura científica, "direito à saúde" pode ser conceituado como: a garantia normativa (aspecto legislativo), a realização prática individual e coletiva (aspecto sociopolítico), a responsabilidade moral (aspecto bioético) e o reconhecimento da exigibilidade (aspectos das demandas específicas) - e, repetindo, em determinado contexto - da atenção ao completo bem-estar físico, mental e social (saúde) ou ao equilíbrio vital integral do ser humano (outra forma possível de se conceituar saúde, numa perspectiva mais integradora).

É importante frisar que este conceito tem significado multidimensional, o que é diferente de dizer que há distintas acepções para o direito à saúde. Faz-se esta afirmação para alertar os pesquisadores de que, ao acolherem o conceito aqui trabalhado, não se limitem a utilizar arbitrariamente um dos aspectos encontrados, mas que considerem todos os aspectos como partes de um todo orgânico, cada um com sua importância fundamental para a construção do conceito mais amplo. 
Além disso, não deve se limitar o pesquisador aos desdobramentos aqui encontrados em relação aos aspectos conceituais do direito à saúde. Como se trata de uma proposta de conceito funcional para pesquisas qualitativas, o pesquisador terá mais proveito se utilizar mais elementos para refinar o conceito de direito à saúde, adaptando-o ao teor de sua pesquisa - incluindo suas experiências, sua vivência acadêmica e a visão de mundo abordada em sua trajetória.

\section{Considerações finais}

A partir da noção de frameworks conceituais, esta produção mostrou a relevância de sua aplicabilidade teórica em estudos científicos no que tange ao desenvolvimento de um percurso viável de estudo, a fim de contemplar os elementos essenciais do objeto que se pretende investigar. Entretanto, as considerações aqui apresentadas não excluem o trabalho de pesquisadores na elaboração de seus próprios frameworks conceituais. O que se mostra aqui são indicações fundamentadas que podem norteá-los na realização de um estudo mais consistente e focalizado.

Esse referencial revela que será preciso tempo e feedback da comunidade científica para identificar os pontos fortes e as falhas do conceito de direito à saúde aqui construído. Diante da escassez de esforços conceituais nessa área, vislumbra-se um possível campo de ricas discussões e utilidade prática deste conteúdo para pesquisadores que enveredam pela pesquisa qualitativa. Terão agora menos dificuldade para situar seus trabalhos e mesmo para organizar seus respectivos métodos de fundamentação teórica, uma vez que as dimensões do conceito proposto servirão como um roteiro para contextualização dos problemas de pesquisa, adicionando o tempero interdisciplinar tão necessário aos estudos de direito e saúde.

\section{Referências}

ASSIS, Marluce Maria Araújo; GONÇALVES, Maria de Lourdes; MATOS, Maria Socorro. Atenção primária de saúde $\mathrm{x}$ sistema único de saúde: apontamentos para um debate. Revista Baiana de Enfermagem, Salvador, v. 6, n. 2, p. 78-88, out. 1993.

DALLARI, Sueli Gandolfi. O direito à saúde. Revista de Saúde Pública, São Paulo, v. 22, n. 1, p. 57-63, 1988. Disponível em: <http://www.scielo.br/pdf/rsp/v22n1/08.pdf>. Acesso em: 14 jan. 2016.

A saúde do brasileiro. São Paulo: Moderna, 1978.

et. al. Advocacia em saúde no Brasil contemporâneo. Revista de Saúde Pública, São Paulo, v. 30, n. 6, p. 592-601, 1996. Disponível em: <http://www.scielo.br/pdf/rsp/ v30n6/5117.pdf>. http://dx.doi.org/10.1590/S0034-89101996000600014. 
Direito à saúde: conceito para a operacionalização de pesquisas qualitativas

FEUERWERKER, Laura. Modelos tecnoassistenciais, gestão e organização do trabalho em saúde: nada é indiferente no processo de luta para a consolidação do SUS. Interface, Botucatu, v. 9, n. 18, p. 489-506, set./dez. 2005. Disponível em: <http://www.scielosp.org/pdf/icse/v9n18/ a03v9n18.pdf>. Acesso em: 18 fev. 2016. http://dx.doi.org/10.1590/S1414-32832005000300003.

GÓMEZ GUCHEA, Hugo Francisco. Ética médica. Revista Medica de Tucumán, Tucumán, v. 8, n. 3, p. 109-116, 2002.

GORNES, Fabíola Zioni; ADORNO, Rubens de Camargo Ferreira. Criança e menor na sociedade brasileira: serviços, cuidados e exclusão. Revista Brasileira de Crescimento e Desenvolvimento Humano, São Paulo, v. 1, n. 1, p. 41-48, jan./jun. 1991. Disponível em: <http://www.revistas.usp.br/jhgd/article/viewFile/37412/40127>. Acesso em: 10 fev. 2016. http://dx.doi.org/10.7322/jhgd.37412.

GRACIA, Diego. What constitutes a just health services system and how should scarce resources be allocated? Bulletin of the Pan American Health Organization, Washington, v. 24, n. 4, p. 550-565, 1990. Disponível em: <http://hist.library.paho.org/English/BUL/ ev24n4p550.pdf>. Acesso em: 20 dez. 2015.

GREEN, Helen Elise. Use of theoretical and conceptual frameworks in qualitative research. Nurse Researcher, London, v. 21, n. 6, p. 34-38, Jul. 2014. Disponível em: <http://journals. rcni.com/doi/pdfplus/10.7748/nr.21.6.34.e1252>. http://dx.doi.org/10.7748/nr.21.6.34.e1252.

HART, Herbert Lionel Adolphus. O conceito de direito. 2. ed. Lisboa: Fundação Calouste Gulbenkian, 1994.

MINAYO, Maria Cecília de Souza. O desafio do conhecimento: pesquisa qualitativa em saúde. 14. ed. São Paulo: Hucitec, 2014.

NOVAES, Ricardo Lafetá. Sobre a homeopatia. Saúde em Debate, Rio de Janeiro, n. 23, p. 85-94, dez. 1988.

PADRÃO, Messias Ligouri. O estatuto do doente mental. Saúde em Debate, Rio de Janeiro, n. 37, p. 11-15, dez. 1992.

PAIVA, Miriam Santos. O direito à saúde. Revista Baiana de Enfermagem, Salvador, v. 4, n. 2, p. 63-79, dez. 1988.

PITTA, Ana Maria Fernandes; DALLARI, Sueli Gandolfi. A cidadania dos doentes mentais no sistema de saúde do Brasil. Saúde em Debate, Rio de Janeiro, n. 36, p. 19-23, out. 1992.

QUINTO NETO, Antônio. A reforma psiquiátrica no Rio Grande do Sul: do direito ao tratamento aos direitos de cidadania do doente mental. Saúde em Debate, Rio de Janeiro, n. 37, p. 5-10, dez. 1992.

ROCCO, Tonette S.; PLAKHOTNIK, Maria S. Literature reviews, conceptual frameworks, and theoretical frameworks: terms, functions, and distinctions. Human Resource Development Review, Thousand Oaks, v. 8, n. 1, p. 120-130, Mar. 2009. Disponível em: <https://www. researchgate.net/publication/249673870 >. http://dx.doi.org/10.1177/1534484309332617. 
SANTOS, Luis A. de Castro. A vez da mulher camponesa: movimento social, identidade e saúde no Maranhão. Revista Brasileira de Estudos de População, Rio de Janeiro, v. 20, n. 1, p. 43-62, jan./jun. 2003. Disponível em: <http://rebep.org.br/index.php/revista/article/ viewFile/303/pdf_284>. Acesso em: 13 fev. 2016.

SILVA, Plácido. Vocabulário jurídico. 27. ed. Rio de Janeiro: Forense, 2008.

SPOSATI, Aldaísa; LOBO, Elza. Controle social e políticas de saúde. Cadernos de Saúde Pública, Rio de Janeiro, v. 8, n. 4, p. 366-378, out./dez. 1992. Disponível em: <http://www. scielo.br/pdf/csp/v8n4/v8n4a03>. http://dx.doi.org/10.1590/S0102-311X1992000400003.

WORLD HEALTH ORGANIZATION. Constitution. 1946. Disponível em: <http://www. who.int/governance/eb/who_constitution_en.pdf>. Acesso em: 14 maio 2016.

YAMIN, Alicia Ely. Dignidad y bienestar. El valor de las técnicas y metodologías médicas en la promoción de los derechos humanos: el caso estudio de México. Cuadernos Médico Sociales, Rosário, n. 74, p. 5-23, 1998. Disponível em: <http://hdl.handle.net/1928/4613>. Acesso em: 20 nov. 2015.

Gustavo D’Andrea - Doutor em Ciências pela Escola de Enfermagem de Ribeirão Preto da Universidade de São Paulo; mestre em Ciências pela Faculdade de Filosofia, Ciências e Letras de Ribeirão Preto da Universidade de São Paulo; bacharel em Ciências Jurídicas e Sociais pela Universidade de Ribeirão Preto. Professor da Universidade Paulista. Ribeirão Preto/SP, Brasil.E-mail: dandrea@usp.br.

Anna Maria Meyer Maciel Rodríguez - Doutoranda e mestre em Ciências pela Escola de Enfermagem de Ribeirão Preto da Universidade de São Paulo; especialista em Enfermagem em Saúde Pública pela Universidade Federal de São Paulo; graduada em Enfermagem pela Universidade de Santo Amaro. Ribeirão Preto/SP, Brasil.

Carla Aparecida Arena Ventura - Livre-Docente pela Escola de Enfermagem de Ribeirão Preto da Universidade de São Paulo (EERP-USP); doutora em Administração pela Universidade de São Paulo; mestre em Direito pela Universidade Estadual Paulista Júlio de Mesquita Filho (Unesp); graduada em Direito pela Unesp; graduada em Relações Internacionais pela Universidade de Brasília. Professora associada da EERP-USP. Ribeirão Preto/SP, Brasil.

Silvana Martins Mishima - Livre-Docente pela Escola de Enfermagem de Ribeirão Preto da Universidade de São Paulo (EERP-USP), doutora e mestre em Enfermagem pela Universidade de São Paulo (USP); especialista em Saúde Pública pela USP, graduada em Enfermagem pela USP. Professora titular da EERP-USP. Ribeirão Preto/SP, Brasil. 